\title{
Study on the Measurement of New Urbanization Level in West China Based on Grey Relational Projection Method
}

\author{
Hongmei Zhang ${ }^{1,2,3}$ Xin $\mathrm{He}^{1,2,3}$
}

\author{
${ }^{1}$ Guizhou University of Finance and Economics, Institute of Finance \\ ${ }^{2}$ Guizhou Institution for Technology Innovation \& Entrepreneurship Investment \\ ${ }^{3}$ Guizhou Institute of Urban Economics and Development Guiyang Guizhou 550025, \\ China
}

\begin{abstract}
Urbanization is the motive force for the long-term and steady development of China's economy, its manifestation is not only the spatial transfer of population, but also the adjustment of industrial structure, the improvement of ecological environment and so on. In this paper, the grey Relation projection method is used to construct the evaluation system of the new urbanization level in the western region, and the new urbanization level of 12 provinces, cities and autonomous regions in China is measured according to the data of urbanization, urbanization, urbanization, urbanization and ecological urbanization in the 2015. The results show that there are some differences in the development of urbanization in provinces and cities.
\end{abstract}

\section{Keywords}

New urbanization; Grey relational projection method; Western Region; Level measure

\section{基于灰色关联投影法的西部地区新型城 镇化水平测度研究}

\author{
张红梅 $1,2,3$ 何欣 $1,2,3$ \\ 1 贵州财经大学, 金融学院 \\ 2 贵州科技创新创业投资研究院 \\ 贵州城镇经济与发展研究院, 贵州, 贵阳 550025
}

摘要: 城镇化是我国未来经济长期稳定发展的动力, 其表现形式不仅仅是人口的空间转移, 也包含产业结构的调整、生态环境的改进等等各个层面。本文采用灰色关联投影法构建西部 地区新型城镇化水平评价体系，根据 2015 年人口城镇化、经济城镇化、生活城镇化、空间 城镇化、生态城镇化五个社会层面的数据测算我国西部地区 12 个省市、自治区的新型城镇 化水平。分析结果表明各省市自治区城镇化发展并不均衡，存在一定差异。

关键词：新型城镇化；灰色关联投影；西部地区；水平测度号 


\section{1. 引言}

城镇化的最基本概念是农村人口 向城镇人口转化的过程, 主要表现为 农村人口在城镇中生活工作, 接受城 市文明和文化观念, 成为城镇中的市 民, 拥有城镇居民的医疗等社会保障 服务。城镇化过程中最主要的特征表 现为城镇数目的增多和人口总量的扩 大。而实施新型城镇化战略有利于扩 大国内市场有效需求, 促进农村社会 经济的发展, 成为拉动我国经济增长 最有效的支撑点。在过去改革开放的 三十几年里, 我国城镇化水平发展迅 猛, 走出了一条其他国家想都不敢想 的城镇化道路。而在关键的历史时 期, 我国又根据历史形势和国际经验 提出了新型城镇化, 旨在全面地实现 小康社会的奋斗目标, 新型城镇化不 仅仅是对传统城镇化发展模式的摒 弃, 更是对传统城镇化发展模式的一 种升级。

\section{2. 国内外文献回顾}

\section{1. 国外研究现状}

城镇化基本理论研究。Max Weber (1899) ${ }^{[1]}$ 最早提出了城镇化的 概念。他认为西方国家的城镇化是伴 随着工业化的发展而兴起的。 Christaller (1933) ${ }^{[2]}$ 通过多年调 ${ }^{1}$

\footnotetext{
${ }^{1}$ 基金项目: 本文由贵州省科技计划项目 （黔科合基础 [2016] 1534-4 号）资助，项 目名称: 贵州新型城镇化金融支持效率研 究。

作者简介: 张红梅, 教授、硕士生导师, 任职于贵州财经大学金融学院, 研究方

向: 金融与区域发展、创业投资、风险分 析与管理。Email: 754560989@qq. com。何 欣, 男, 贵州财经大学金融学院研究生硕 士。贵州财经大学在读研究生, 研究方 向：金融与区域发展、创业投资、风险分 析与管理, Email: 121190731@qq.com。
}

查、研究德国南部城镇的空间组织与 布局, 首创了“中心学说理论”, 认 为城镇的发展离不开土地和人口的支 撑，同时中心城镇与周边的城镇、农 村之间都是相互依存的。Kuznets

(1966) ${ }^{[3]}$ 认为城镇化是农村人口向城 镇转移的过程, 即城镇人口比重不断 增加的过程。Friedman (1976) ${ }^{[4]}$ 则更 为细致地解释了城镇化, 他认为城镇 化不仅仅是人口的单纯转移, 还包括 非农的生产活动随之转移, 城镇生活 方式、城镇精神文化随之扩散的过 程。

城镇化评价方法研究。Cloke (1977 $)^{[5]}$ 根据人口、职业、居住环境 及与城市中心的距离等 16 个指标评价 城镇化, 由于当时是针对英国的实际 情况制定且时间较久, 其中部分指标 在现在看来并不合理。Alexi Inkeles, David・H・Smith (1992) ${ }^{[6]}$ 建立的城市 现代化指标体系包含了人口自然增长 率、非农就业者占总就业者的比重、 非农产业占 GDP 的比重等 10 项指 标, 这套指标偏重于 GDP, 而 GDP 只 是经济增长的代表, 并不意味着居民 生活水平的提高, 尤其是环境质量的 改善。

\section{2. 国内研究现状}

城镇化基本理论研究。王素斋, 许经勇（2013） ${ }^{[7]}$ 认为城镇化是指农村 人口向城市转移的过程。同时，他们 认为这种人口转移的原因是地区经济 的发展, 从而导致劳动人口的集聚, 第一产业的从业人员向二三产业转 移。齐成喜 (2005) ${ }^{[8]}$ 认为城镇化是农 村和城市间的一种协调发展, 通过城 镇规模的不断扩张, 达到城乡一体的 效果。苏发金 (2011) ${ }^{[9]}$ 则认为城镇化 随着农村人口和一些经济社会要素向 城镇转移的过程, 城镇数量不断增 加, 城镇规模不断的扩大。徐光平 
(2011) ${ }^{[10]}$ 认为城镇化就是遵从市场 经济发展的规律，资源在市场的导向 下，流向效益高的二三产业，从而使 整个社会处于帕累托最优状态。张占 斌, 程怀儒 (2013) ${ }^{[11]}$ 认为城镇化的 发展方式就是农村的各种要素向城镇 转移, 包括资本、劳动力、土地等 等, 本质目的就是工业化。原新和唐 晓平 (2006) ${ }^{[12]}$ 认为新型城镇化发展 应经济社会与生态效益两手抓, 达到 双赢效果。

城镇化发展水平的评价研究。张 占仓 (2012) ${ }^{[13]}$ 为了探讨中部省份城 镇化发展水平的差距, 则对中部六省 的城镇化水平进行了横向的对比, 比 较中部六省城镇化发展过程中的优势 及劣势, 并得出其发展不均衡的结 论。陈明星（2009） ${ }^{[14]}$ 则从人口、经 济、生活、科技、环境六个方面来考 虑城镇化的问题。楚爱丽 (2011) 则分析了城镇化人口的影响因素，利 用城镇人口所占比重、第二三产业从 业人员比重等可以反映人口变化的指 标对城镇化水平进行分析。郝华永 (2011) ${ }^{[16]}$ 则从城镇化发展潜力、城 镇化发展装备、城镇化发展经济三个 角度去分析城镇化发展, 并以这三个 角度选择相应的指标, 城镇化评价体 系。

\section{3. 灰色关联投影模型的建立}

\section{1. 灰色关联投影法的基本原理}

灰色关联投影法是从矢量投影的 角度出发解决多目标决策与评价问 题。该方法的决策方案与因素指标集 相对应。灰色关联投影法通过以每个 方案在理想方案上的投影值大小，作 为评判决策方案优劣的标准, 然后根 据指标的重要程度确定指标权重, 从 而全面准确地反映了各决策方案和理 想方案之间的接近程度, 使得西部地
区各省市、自治区新型城镇化发展的 评价更接近客观实际。

\section{2. 灰色关联投影模型的建立}

（1）构造多指标决策域集合与因 素指标集合, 然后找出最佳决策方案 集 $C_{0}$ 的因素指标集 $W_{0}$ 的属性值 $T_{0 j}$ 。 最后列出多指标决策域集合 $C$ 对因素 指标集 $W$ 的决策矩阵 $T$ 。设多指标决 策域集合 $C=\{$ 方案 1 , 方案 $2, \cdots$, 方案 $\mathrm{n}\}=\left\{C_{1}, C_{2}, \cdots, C_{\mathrm{n}}\right\}$ 因素指 标 集 合 $W=\{$ 指标 1 , 指标 $2, \cdots$ 指标 $\mathrm{m}\}=\left\{N_{\mathrm{l}}, N_{2}, \cdots, N_{\mathrm{m}}\right\}$ 记决策方案 $C_{i}$ 对指标 $N_{j}$ 的属性值记为 $T_{i j}(i=1,2, \cdots n ; j=1,2, \cdots m) 。$

构建方案集 $C$ （包括最佳决策方 案集 $C_{0}$ ）对指标集 $W$ 的属性值矩阵

$$
\begin{aligned}
& T \text { 。 有 : } \quad T=\left(T_{i j}\right)_{(n+1) m}, \\
& (i=0,1,2, \cdots, n ; j=1,2, \cdots m) 。
\end{aligned}
$$

(2) 数据初值化处理和关联度的 计算。决策之前首先应将评价指标进 行无量纲化处理。所谓的处置化处理 是对一个数列的所有数据均除以它的 第一个数据, 从而得到新的数据列的 方法叫做初值化处理。所以对决策矩 阵 $T=\left(T_{i j}\right)_{(n+1) m}$ 进行初值化生成矩阵 $H=\left(H_{i j}\right)_{(n+1) m}$ 。而理想方案为:

$$
H_{0 j}=1,(j=1,2, \cdots m) \circ
$$

由于每一个方案是由 $m$ 个因素指 标所决定的, 所以它就构成了 $m$ 维因 素指标空间 $V$ 中的一个离散的方案 点, 进行多目标决策就是比较空间 $W$ 中各方案点与理想方案点的关联度。 以 $H_{0 j}(j=1,2, \cdots m)$ 为母因素, 以 $H_{i j}(i=1,2, \cdots n ; j=1,2, \cdots m)$ 为子因 素, 就可以得到其他方案与理想方案 的关联度。记 $K_{i j}$ 为子因素 
$H_{i j}(i=1,2, \cdots n ; j=1,2, \cdots m)$ 关于母因 素 $H_{0 j}=1,(j=1,2, \cdots m)$ 的关联度, 则 $\mathrm{K}_{\mathrm{ij}}=\frac{\min \min \left|H_{0 j}-H_{i j}\right|+\lambda \max \max \left|H_{0 j}-H_{i j}\right|}{\left|H_{0 j}-H_{i j}\right|+\lambda \max \max \left|H_{0 j}-H_{i j}\right|}$

其中 $\lambda=0.5$ 。

（3）构造灰色关联度判断矩阵。 由 $(n+1) \times m$ 个 $K$ 组成的矩阵为多目标 灰色关联度判断矩阵 $F$ 。则有:

$L=\left(\begin{array}{cccc}K_{01} & K_{02} & \cdots & K_{0 \mathrm{~m}} \\ K_{11} & K_{12} & \cdots & K_{\mathrm{lm}} \\ \vdots & \vdots & \ddots & \vdots \\ K_{\mathrm{n} 1} & K_{\mathrm{n} 2} & \cdots & K_{\mathrm{nm}}\end{array}\right)=\left(\begin{array}{cccc}1 & 1 & \cdots & 1 \\ K_{11} & K_{12} & \cdots & K_{1 \mathrm{~m}} \\ \vdots & \vdots & \ddots & \vdots \\ K_{\mathrm{n} 1} & K_{\mathrm{n} 2} & \cdots & K_{\mathrm{nm}}\end{array}\right)$

（4）确定每个指标的权重及加权 关联决策矩阵。在研究多指标因素的 影响评价中, 由于各指标因素对方案 的影响程度不同, 所以确定各指标的 权重系数是非常关键的环节。然而, 对指标赋权的方法很多, 归纳起来大 致可以分为两大类: 既主观赋权法和 客观赋权法。基于各种因素的考虑, 本文选取主观赋权法中的层次分析法 (AHP )，根据各指标在评价新型城 镇化中的重要程度, 确定其相应权 重。其权重表达式如下:

$$
Z=\left(\mathrm{z}_{1}, \mathrm{z}_{2}, \cdots \mathrm{z}_{\mathrm{j}}, \cdots \mathrm{z}_{\mathrm{m}}\right) 。
$$

再由 $\mathrm{I}=\mathrm{L} \times \mathrm{Z}$ 确定加权灰色关联决策 矩阵则有:

$I=\left(\begin{array}{cccc}1 & 1 & \cdots & 1 \\ K_{11} & K_{12} & \cdots & K_{1 \mathrm{~m}} \\ \vdots & \vdots & \ddots & \vdots \\ K_{\mathrm{m} 1} & K_{\mathrm{n} 2} & \cdots & K_{\mathrm{nm}}\end{array}\right) \times\left(\begin{array}{c}\mathrm{z}_{1} \\ \mathrm{z}_{2} \\ \vdots \\ \mathrm{z}_{\mathrm{m}}\end{array}\right)=\left(\begin{array}{cccc}\mathrm{z}_{1} & \mathrm{z}_{2} & \cdots & \mathrm{z}_{\mathrm{m}} \\ \mathrm{z}_{111} & \mathrm{z}_{2} K_{12} & \cdots & \mathrm{z}_{\mathrm{m}} K_{1 \mathrm{~m}} \\ \vdots & \vdots & \ddots & \vdots \\ \mathrm{z}_{1} R_{\mathrm{n} 1} & \mathrm{z}_{2} K_{\mathrm{n} 2} & \cdots & \mathrm{z}_{\mathrm{m}} K_{\mathrm{nm}}\end{array}\right)$

（5）计算各个决策方案 $C_{i}$ 在理想 方案 $C_{0}$ 上的投影值。将每个决策方案 看成一个行向量 (矢量), 则称每个 决策方案 $C_{i}$ 与理想方案 $C_{0}$ 之间的夹角 $\phi$ 为灰色关联投影角。夹角余弦越 大, 表明决策方案 $C_{i}$ 与理想方案 $C^{*}$ 之 间的变化方向越一致。夹角余弦值 为: $\cos \phi_{i}=\frac{C_{i} \times C_{0}}{\left\|C_{i}\right\| \times\left\|C_{0}\right\|}=\frac{\sum_{j=1}^{m} z_{j} \times K_{i j} \times z_{j}}{\sqrt{\sum_{j=1}^{m}\left(z_{j} K_{i j}\right)^{2}} \times \sqrt{\sum_{j=1}^{m} z_{j}^{2}}}=\frac{\sum_{j=1}^{m} z_{j}^{2} \times K_{i j}}{\sqrt{\sum_{j=1}^{m}\left(z_{j} K_{i j}\right)^{2}} \times \sqrt{\sum_{j=1}^{m} z_{j}^{2}}}, i=1,2 \cdots n$

将模的大小与夹角余弦的大小综 合考虑, 就可以全面准确的反应各个 决策方案 $\mathrm{C}_{\mathrm{i}}$ 与理想方案 $\mathrm{C}_{0}$ 之间的接近 程度。称决策方案 $\mathrm{C}_{\mathrm{i}}$ 在理想方案 $\mathrm{C}_{0}$ 上 的投影值为灰色关联投影值 $\mathrm{Si}$, 则:

$$
S_{\mathrm{i}}=\left\|C_{\mathrm{i}}\right\| \times \cos \phi_{\mathrm{i}}=\left\|C_{\mathrm{i}}\right\| \times \frac{C_{\mathrm{i}} \times C_{0}}{\left\|C_{\mathrm{i}}\right\| \times\left\|C_{0}\right\|}=\frac{\sum_{\mathrm{i}=1}^{\mathrm{m}} K_{\mathrm{ij}} \times \mathrm{z}_{\mathrm{j}}^{2}}{\sqrt{\sum_{\mathrm{j}=1}^{\mathrm{m}} \mathrm{z}_{\mathrm{j}}^{2}}}=\sum_{\mathrm{j}=1}^{\mathrm{m}} K_{\mathrm{ij}} \times\left(\frac{\mathrm{z}_{\mathrm{j}}^{2}}{\sqrt{\sum_{\mathrm{j}=1}^{\mathrm{m}} \mathrm{z}_{\mathrm{j}}^{2}}}\right)
$$

（6）灰色关联投影值 $\mathrm{S}_{\mathrm{i}}$ 综合的反 映了决策方案 $\mathrm{C}_{\mathrm{i}}$ 与理想方案 $\mathrm{C}_{0}$ 之间的 接近程度。最后根据 $\mathrm{S}_{\mathrm{i}}$ 的大小对各决 策方案进行排序。 $\mathrm{S}_{\mathrm{i}}$ 越大, 说明该方案 与理想方案与接近, 则该方案越优 秀。

\section{4. 实证分析}

\section{1. 指标体系的建立与数据的来源}

本文立足于新型城镇化的各个系 统层面, 基于新型城镇化综合指标评 价原则, 主要选取人口城镇化、经济 城镇化、生活城镇化、空间城镇化及 生态城镇化作为一级指标, 并从这五 个层面分别阐述城镇化的含义，同时 选取了这 5 个一级指标下设的 16 个二 级指标。如表 1 所示:

表 1 新型城镇化指标体系

\begin{tabular}{l|c|c}
\hline \multirow{4}{*}{} & 一级指标 & 二级指标 \\
\cline { 2 - 3 } & 人口城镇化 & 城市人口密度 \\
\cline { 3 - 3 } 新 & $\left(\mathrm{X}_{1}\right)$ & 城镇人口比重 \\
\cline { 3 - 3 } 型 & & 人均 GDP \\
\cline { 3 - 3 } 城 & 经济城镇化 & 工业产值占 GDP 比重 \\
\cline { 3 - 3 } 镇 & $\left(\mathrm{X}_{2}\right)$ & 第三产业占 GDP 比重 \\
\cline { 3 - 3 } 化 & & 城镇固定资产占总投资比重 \\
\cline { 3 - 3 } 指 & & 燃气普及率 \\
\cline { 3 - 3 } 标 & 生活城镇化 & 城镇居民人均消费水平 \\
\cline { 3 - 3 } 体 & $\left(\mathrm{X}_{3}\right)$ & 城镇居民人均可支配收入 \\
\cline { 3 - 3 } & 每万人拥有公共交通车辆 \\
\hline
\end{tabular}




\begin{tabular}{c|c|c}
\hline 系 & & (标台) \\
\cline { 2 - 3 } & \multirow{2}{*}{$\begin{array}{c}\text { 空间城镇化 } \\
\left(\mathrm{X}_{4}\right)\end{array}$} & 人均拥有建成区面积 \\
\cline { 2 - 3 } & 人均拥有城市道路面积 \\
\cline { 2 - 2 } & 人均拥有城区面积 \\
& $\begin{array}{c}\text { 生态城镇化活垃圾处理率 } \\
\left(\mathrm{X}_{5}\right)\end{array}$ & 人均公园绿地面积 \\
\cline { 3 - 3 } & $\begin{array}{c}\text { 城市污水日处理能力 (万立 } \\
\text { 方米) }\end{array}$ \\
\hline
\end{tabular}

\section{2. 数据的处理分析}

（1）构造多指标决策域集合与因 素指标集合。根据上表数据: 多指标 决策域集: $\mathrm{C}=\{$ 内蒙古, 广西, 重庆, 四川, 贵州, 云南, 西藏, 陕西, 甘 肃, 青海, 宁夏, 新疆 $\}$; 因素指标集

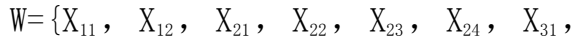
$X_{32}, X_{33}, X_{34}, X_{41}, X_{42}, X_{43}, X_{51}, X_{52}$, $\left.X_{53}\right\}$ 。根据指标性质和原始数据可知最 佳方案 $\mathrm{C}_{0}=\{4049 ， 0.61 ， 71101$, $0.5,0.54,1.00,97.63$, 21876.47, 30594.1, 16.08, 1.61, $24.98,5.74,98.7,19.28$, 689.63 。其中西部各省市、自治区的 指标均为 “效益” 型指标, 即: 各个 指标的属性值越大, 它所代表的新型 城镇化发展水平越高。前面公式得出 方案集 $C$ 对指标集 $W$ 的属性值矩阵为 $\mathrm{T}$ 。

（2）数据初值化处理以及构造关 联度判断矩阵。对一个数列的所有数 据均除以它的第一个数据从而得到新 的数据序列。根据上式得方案集 $\mathrm{C}$ 对 指标集 $W$ 的属性值矩阵的初始化矩阵 $H$ 和灰色关联度判断矩阵 L。

（3）运用层次分析法（AHP）确 定指标的权重系数并计算加权关联决 策矩阵。根据已经建立的新型城镇化 指标体系构建层次结构模型, 计算权 向量, 做一致性检验并计算权重值 Z; 再由 $\mathrm{I}=\mathrm{L} \times \mathrm{Z}$ 确定加权灰色关联决策矩 阵 $\mathrm{I}$ 。
（4）计算各个决策方案 $C_{i}$ 在理想 方案 $\mathrm{C}_{0}$ 上的投影值, 得决策方案在理想 方案上投影值的向量。则:

$$
\begin{aligned}
& D=\left(\begin{array}{lll}
0.00393 & 0.00311 & 0.00353
\end{array}\right. \\
& \begin{array}{llll}
0.00313 & 0.00282 & 0.00287 & 0.00292
\end{array} \\
& \begin{array}{lll}
0.00339 & 0.00287 & 0.0309
\end{array} \\
& \left.\begin{array}{ll}
0.00307 & 0.00307
\end{array}\right)
\end{aligned}
$$

通过上述结果可知: 基于灰色关 联投影法对西部地区新型城镇化发展 水平进行测度, 测度结果显示西部地 区新型城镇化发展水平排名前三位分 别是内蒙古 (0.00393) 、重庆 （0.00353）、陕西（0.00339）；而 贵 州（０.00282）、云 南 (0.00287) 、甘肃（0.00287）新型 城镇化发展水平最低, 排名西部地区 新型城镇化发展发展水平靠后; 宁夏 (0.00337)、四川 (0.00313)、广 西（0.00311）、青海（0.00309）、 新疆 $(0.00307)$ 在西部地区新型城镇 化水平属于中等水平。

\section{5. 结论与讨论}

由于西部各省市自治区的人口、 自然、社会、经济状况存在较大差 异, 所以新型城镇化发展水平也存在 着较大差异。构建科学合理的评价指 标体系, 对新型城镇化全面协调可持 续发展具有重大指导意义。在推进新 型城镇化进程中, 经济动力、人口转 移、生活条件、基础设施、人居环境 是西部地区面临的现实问题，本文基 于灰色关联投影法围绕这五个方面构 建新型城镇评价指标体系。通过计算 新型城镇化指数分析、比较西部各地 区的城镇化发展水平, 有利于对西部 地区新型城镇化状况做出客观与合理 的判断，促使当地政府广泛关注和重 视城镇经济发展、人口转移、基础设 施、人居环境等指标的发展状况。 


\section{参考文献}

[1] MAX WEBER. Measures of Multidimensional Urbanization [J]. Research on Economic Inequality, 1899, 8(4): 175-194.

[2] CHRISTALLER. The Problems in the Course of China's Urbanization [J]. Engineering Education and Management, 1933: 173-177.

[3] KUZNETS. Urbanization Patterns: European versus Less Developed Countries [J]. Journal of Regional Science, 1966, 2: 231-252.

[4] FRIEDMAN. Urbanization and Economic Development: a Bias towards Large Cities [J]. Journal of Urban Economics, 1976, 4(1): 13-37.

[5] Cloke,P.An index of rurality for England and Wales[M]. London: Regional Studies, 1977.

[6] 阿列克斯 - 英克尔斯 戴维 $・ h \cdot$ 斯密 斯.从传统人到现代人一一六个发 展中国家中的个人化. 北京: 中国人 民大学出版社, 1992.1 .

[7] 王素斋. 新型城镇化科学发展的内 涵、目标与路径 $[\mathrm{J}]$. 热点关注， 2013, (4): 165-168.

[8] 齐成喜, 陈柳钦等. 我国农业产业 化与农村城镇化的互动发展研 究。安徽农业科学, 2005, 33(12): 2446-2449.

[9] 苏发金. 城乡统筹: 城镇化与农业 经济增长关系的实证分析 $[\mathrm{J}]$. 经济 经纬, 2011，(4): 111-115.

[10]徐光平. “十二五” 时期协调推进 新型城镇化与新农村建设研究. 东 岳论从，2011，(8): 156-160.

[11]张占斌. 新型城镇化的战略意义和 改革难题 $[\mathrm{J}]$. 国家行政学院学报一 经济发展与改革, 2013，1：4954.

[12]原新, 唐晓平. 都市圈化: 一种新 型的中国城市化战略 $[\mathrm{J}]$. 中国 - 人 口资源与环境，2006，
16(4): 7-12.

[13]张占仓, 孟繁华等. 河南省新型城 镇化实践与对策研究综述 $[\mathrm{J}]$. 管理 学刊, 2012, 8(4): 103-106.

[14] 陈明星, 陆大道等. 中国城市化水 平的综合测度及动力因子分析 [J]. 地理学报，2009，64(4)：387398.

[15]楚爱丽. 加快新型城镇化发展进程 的若干思考 $[\mathrm{J}]$. 农业经济, 2011， (8): 8-10.

[16]郝华永. 基于熵值法的湖北省地级 市城镇化质量实证研究 $[\mathrm{J}]$. 湖北行 政学院学报, 2011，(6): 76-78. 